\title{
EMPREGO DO CAPEAMENTO ESTRUTURAL PARA MELHORIA DO DESEMPENHO DE LAJES ALVEOLARES PROTENDIDAS
}

\author{
Use of the structural concrete topping to improve the \\ performance of hollow core slabs
}

\author{
Bruna Catoia Periotto ${ }^{1}$, Libânio Miranda Pinheiro ${ }^{2}$, Marcelo de Araujo Ferreira ${ }^{3}$
}

Recebido em 16 de fevereiro de 2014; recebido para revisão em 21 de fevereiro de 2014; aceito em 21 de março de 2014; disponível on-line em 21 de maio de 2014.

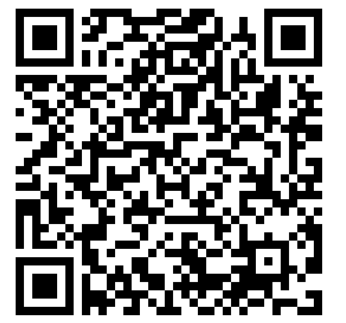

PALAVRAS CHAVE:

Processo construtivo; Desempenho estrutural; Seção composta;

Aderência.

Keywords:

Construction process; Structural performance; Composite section; Adhesion.

\section{* Contato com o autor:}

${ }^{1}$ e-mail : bperiotto@ufscar.br Doutora em engenharia de Estruturas, Universidade Federal de São Carlos (UFSCar),

${ }^{2}$ e-mail : libanio@sc.usp.br ( L. M. Pinheiro)

Professor Doutor da Escola de Engenharia de São Carlos (EESC-USP)

${ }^{3}$ e-mail : marceloaferreira@uol.com.br (M. A. Ferreira)

Professor Doutor da Universidade Federal de São Carlos (UFSCar) slab-topping are identified.

RESUMO: Os elementos para pisos estão entre os produtos pré-moldados mais antigos. As primeiras lajes alveolares foram desenvolvidas na década de 1950, quando evoluíram as técnicas de protensão em longas pistas. A partir do desenvolvimento de pesquisas em produção econômica de unidades com espessuras superiors a $300 \mathrm{~mm}$. Devido a sua ção arrojada, as lajes alveolares podem ser usadas nos mais variados sistemas estruturais, funcionando como laje de piso ou como painéis de fechamento. No Brasil, as a presença de capa de concreto para garantir a integridade estrutural e o efeito diafragma. A crescente utilização de lajes alveolares pelo mercado da construção no Brasil tem causado um aumento significativo na sua produção, demandando uma correta avaliação da efetiva capacidade resistente desses elementos. Entretanto, não existe a padronização de procedimentos técnicos para a execução da capa, que muitas vezes acaba não apresentando aderência satisfatória devido à falta de cuidados durante sua execução. Assim, o processo construtivo da capa pode inviabilizar o comportamento da laje como seção composta, não condizendo com o desempenho previsto em projeto. Este trabalho apresenta as melhorias quanto ao desempenho estrutural de lajes alveolares protendidas

ABSTRACT: The floor elements are among the oldest precast products. The first hollow core slabs were developed in the 1950s, when occured the evolution of prestressing techniques. From the development of research in 1980, there was a technological breakthrough in the production of hollow core slabs being possible the economic production of slabs with thickness higher than $300 \mathrm{~mm}$. Due to its bold design, the hollow core slabs can be used in various structural systems functioning as floor slab or as closure panels. In Brazil, the hollow core units are often used as elements simply supported, with the presence of concrete topping to ensure structural integrity and diaphragm effect. The increase of the use of hollow core slabs for the construction market in Brazil has caused a boost in its production, requiring a correct evaluation of the effective capacity of these elements. However, there is no standardization of technical procedures for the implementation of the concrete topping, and often it is difficulty to achieve satisfactory adhesion due to the lack of care during its execution. Thus, the construction process of the concrete topping can prevent the section work as composed resulting in a different performance than expected in the project. This paper presents the improvements as structural performance of prestressed hollow core slabs considering the use of structural concrete topping. In addition, essential aspects of the process to obtain effective adhesion 


\section{INTRODUÇÃO}

As lajes alveolares protendidas correspondem ao elemento pré-moldado mais utilizado no mundo, dezenas de milhões de metros quadrados de lajes são fabricados todo ano ao redor do mundo, com o emprego predominante na América do Norte e na Europa Ocidental. Nesses países, como são utilizadas lajes alveolares com elevadas alturas, não existe a necessidade do emprego da capa em todas as situações de projeto. Além disso, a não consideração da capa também é possível devido ao emprego de ligações especiais entre as lajes e as vigas, e de melhores juntas longitudinais, com mecanismos desenvolvidos para garantir melhor transferência de cisalhamento.

No Brasil, como as lajes geralmente utilizadas são mais baixas, é usual o emprego de capa para conformação de pavimento composto, que fornece diversas vantagens, como: aumento da capacidade portante do pavimento (melhorando tanto a resistência à flexão como ao cisalhamento); continuidade entre os elementos estruturais e garante o efeito diafragma.

Assim, é de extrema importância que, quando considerada em projeto, a capa efetivamente funcione de forma solidarizada. Entretanto, técnicas incorretas de construção e preparação das superfícies geram problemas para o comportamento global da estrutura, quando considerada de forma monolítica. Frequentemente são ignorados o efeito do teor de umidade, retração ou características da superfície da laje, durante a construção da capa de concreto.

A transferência de cisalhamento horizontal, na interface com a capa moldada no local, é um requisito essencial para assegurar a ação conjunta dos dois elementos.

Quando o concreto moldado no local é lançado em uma unidade pré-moldada, a segurança tem que ser garantida pela aderência e pela resistência ao cisalhamento entre as superfícies de contato. De acordo com a FIP (1982), superfície lisa e limpa tem melhor aderência global do que superfícies rugosas empoeiradas e sujas, onde ocorrem rupturas localizadas da aderência.

Assim, para uma boa aderência é importante que a superfície superior da laje seja rugosa (Figura 1) e que os contaminantes sejam removidos, quer por jato de água, quer por limpeza a vácuo ou a ar comprimido. Limpeza com vassoura não é suficiente para eliminar a poeira localizada nas pequenas depressões da interface.

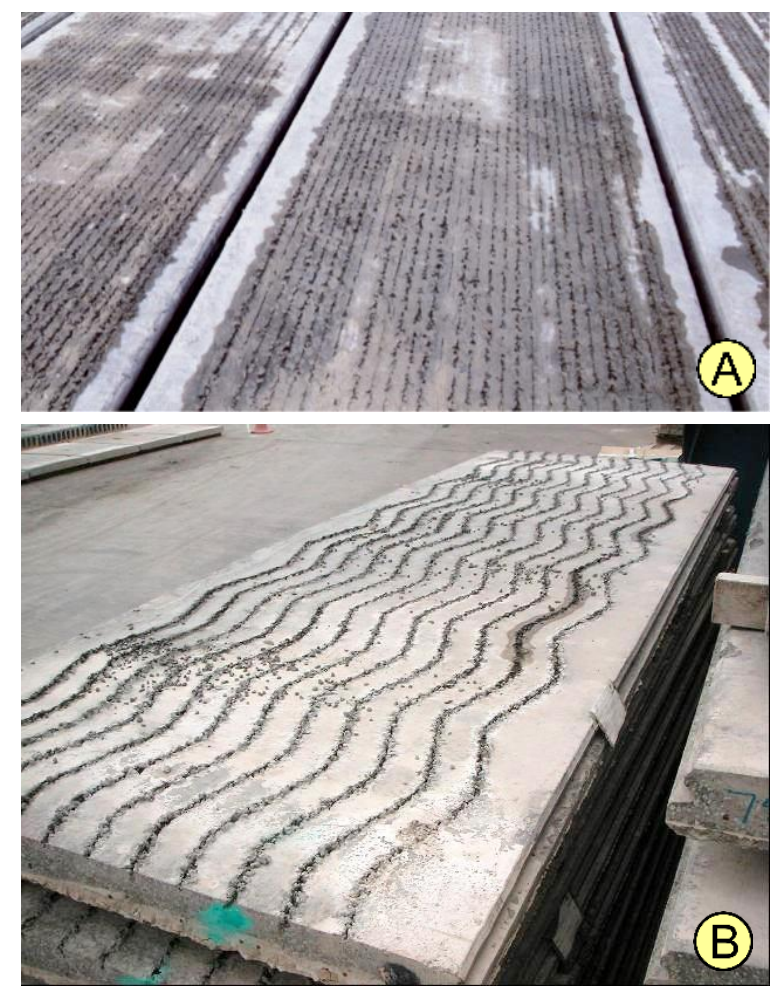

FIGURA 1: Superfície rugosa em lajes alveolares FONTE: A) ELLIOTT (2005), B) IBRAHIM (2008).

Neste trabalho, pretende-se analisar o comportamento das lajes alveolares com capa estrutural, verificando as contribuições do capeamento estrutural no desempenho das unidades alveolares e as alterações nos mecanismos de comportamento próximo à ruína. Para que seja possível esse estudo serão analisadas por meio de ensaios experimentais lajes semelhantes com e sem a presença de capa.

\section{APLICAÇÃO DAS LAJES ALVEOLARES}

Até 1970 , as lajes alveolares foram usadas quase que exclusivamente com apoios simples. As pequenas alturas das lajes então produzidas (12 $\mathrm{cm}, 15 \mathrm{~cm}, 20 \mathrm{~cm}$ e $25 \mathrm{~cm}$ ) não permitiam longos vãos ou grandes cargas.

Com o tempo, foi desenvolvido o conceito de seção composta, proporcionando maior 
eficiência tanto para a laje como para viga, o que conduziu ao crescimento das aplicações das unidades de laje alveolares em pisos e ao uso generalizado desses elementos em todos os tipos de construções.

Assim, as lajes alveolares protendidas préfabricadas passaram a representar uma das soluções estruturais mais avançadas para sistemas de piso, podendo ser utilizadas extensivamente em todo tipo de construção, não somente para estruturas pré-moldadas, mas também em combinação com outros materiais, como por exemplo: estruturas metálicas, de madeira, de concreto moldado no local etc.

Alguns exemplos de aplicações das unidades alveolares em diversos sistemas construtivos podem ser observados na Figura 2 e na Figura 3.
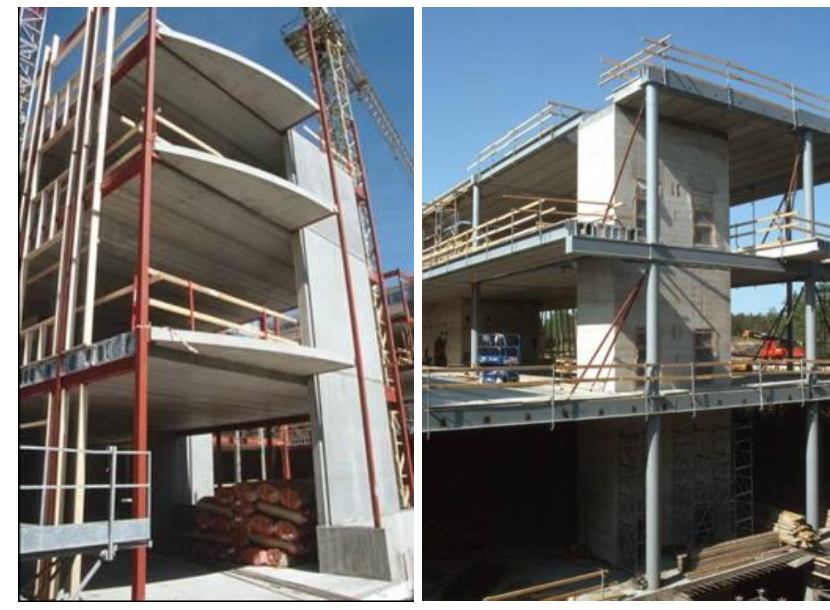

FIGURA 2: Lajes alveolares sobre estruturas metálicas FONTE: ELLIOTT (2005).

Atualmente, lajes alveolares de grandes alturas permitem a construção de pisos com vãos de até $20 \mathrm{~m}$ sob cargas industriais, não mais com apoio simples, mas com restrições de continuidade estrutural e mesmo extremidades engastadas.

Essas possíveis aplicações favoreceram a adoção de pisos de lajes alveolares na construção de obras subterrâneas, onde é de importância primordial a estrutura ser monolítica.

Além disso, a grande versatilidade das lajes alveolares permite que elas também sejam usadas não somente como pisos, mas também como paredes de tanques para tratamento de água, como muros de arrimo e, eficientemente, como paredes externas e estruturais para construções de todos os tamanhos.

Atualmente também está sendo produzido um tipo específico de laje alveolar, com três alvéolos, que é utilizado como arquibancada de estádios.

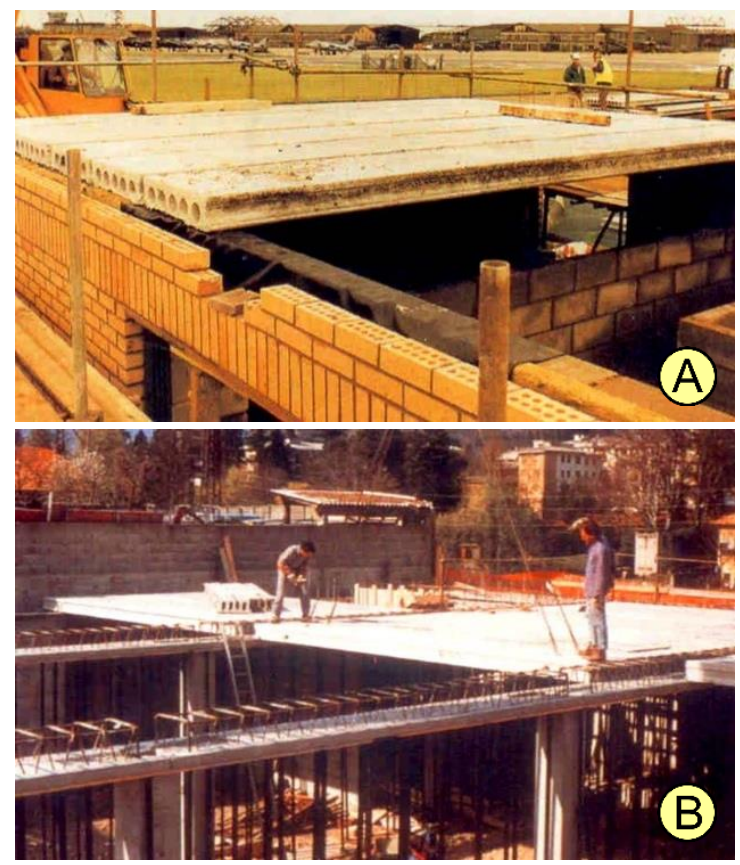

FIGURA 3: A) Lajes alveolares sobre alvenaria estrutural; B) Lajes alveolares sobre concreto moldado no local.

Fonte: ELLIOTT (2005).

\section{MODELO TEÓRICO DE CÁLCULO}

A norma brasileira NBR 14861:2011 apresenta uma expressão (Equação 1) para a verificação da resistência ao cisalhamento de lajes alveolares protendidas com ou sem a presença de capeamento estrutural.

$V_{\mathrm{Rd} 1}=\left[0,25 \cdot f_{\mathrm{ctd}} \cdot \mathrm{k} \cdot\left(1,2+40 \rho_{1}\right)+0,15 \cdot \sigma_{\mathrm{cp}}\right] \cdot \mathrm{b}_{\mathrm{w}} \cdot \mathrm{d} \quad \mathrm{Eq} \cdot[01]$

Onde:

$\mathbf{V}_{\mathbf{R d} 1}$ : resistência de projeto ao cisalhamento $(\mathrm{kN})$;

$f_{c t d}$ : resistência à tração de projeto do concreto prémoldado $f_{c t d}=f_{c t k, \text { inf }} / / \gamma_{c}\left(k N / \mathrm{m}^{2}\right)$;

$\rho_{1}$ : taxa de armadura da seção alveolar prémoldada $\rho_{1}=\frac{A_{s 1}}{b_{w} \cdot d} \leq 0,02$ (adimensional);

$\sigma_{\mathrm{cp}}$ : tensão de compressão do concreto devida à força de protensão $\sigma_{c p}=\frac{N_{s d}}{A_{c}}\left(k N / m^{2}\right)$;

K : coeficiente $k=1,6-d \geq 1$ (adimensional);

$\mathbf{A}_{\mathrm{s} 1}$ : área da armadura de tração $\left(\mathrm{m}^{2}\right)$;

$\mathbf{b}_{\mathrm{w}}$ : largura mínima da seção ao longo da altura útil $\mathrm{d}(\mathrm{m})$; 
$\mathbf{N}_{\text {sd }}$ : força longitudinal na seção devida à protensão ou carregamento (compressão positiva) $(\mathrm{kN})$;

d : altura útil total da seção transversal $(\mathrm{m})$;

De acordo com a NBR 14861 (ABNT 2011), nos cálculos teóricos ao cisalhamento, a Equação 1 deve ser empregada considerando a altura útil, para o caso sem capa e a altura útil total (altura útil da laje somada à altura da capa), para o caso com capa.

\section{ESTUDO EXPERIMENTAL}

A resistência das lajes alveolares ao cisalhamento está totalmente relacionada com a resistência do concreto à tração, uma vez que esse tipo de laje não possui qualquer armadura transversal. Além disso, a resistência ao corte também é diretamente influenciada pela forma geométrica dos alvéolos, pela dosagem do concreto e pelo processo de fabricação. A resistência do concreto à tração é difícil de ser determinada a partir de métodos tradicionais, e a influência da forma da seção transversal e do método de fabricação não pode ser determinada diretamente. Assim, foi desenvolvido um ensaio padrão para determinar a resistência das lajes alveolares ao cisalhamento, para verificar o funcionamento da extrusora e, também, para determinar alguns parâmetros relacionados à capacidade resistente de apoio. Tal ensaio padrão é indicado no manual da FIP (1992) e na norma europeia EN 1168 (CEN 2005) e pode ser observado na Figura 4.

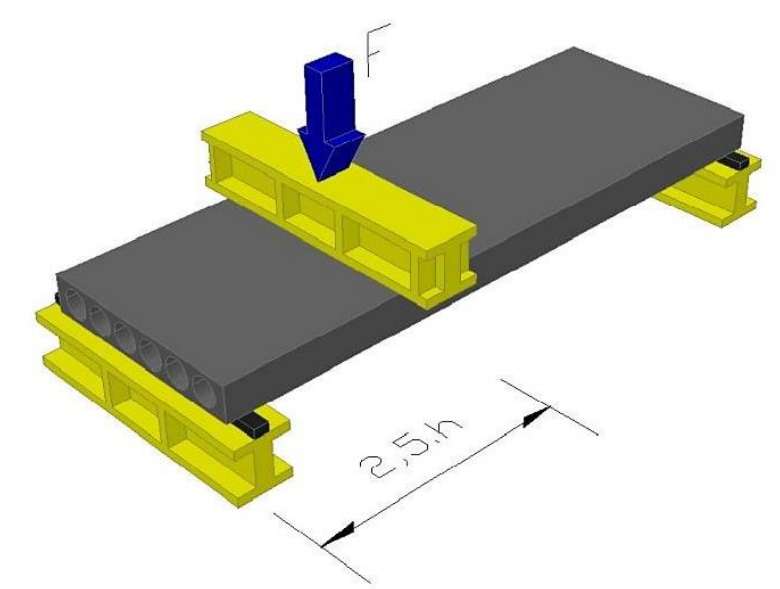

FIGURA 4: Ensaio padrão de cisalhamento (com h igual a altura da laje).

FONTE: CATOIA (2011).

Com relação ao cisalhamento em lajes alveolares protendidas, a nova proposta de revisão da EN 1168 (CEN 2005) estabelece dois critérios para avaliar a confiabilidade de um modelo de projeto. Considerando cada ensaio isoladamente, a relação entre a força cortante última obtida no ensaio $\left(V_{\text {ensaio }}\right)$ e a força cortante última calculada $\left(V_{\text {calc }}\right)$ deve ser maior ou igual a 0,95. Considerando o valor médio de três ensaios, a relação entre $V_{\text {ensaio }}$ e $V_{\text {calc }}$ deve ser maior ou igual a 1.

\subsection{DESCRIÇÃO DOS MODELOS}

Os modelos foram compostos por lajes alveolares protendidas produzidas por duas empresas, denominadas de $\mathrm{X}$ e Z. No Quadro 1 pode-se observar a caracterização dos modelos.

\begin{tabular}{|c|c|c|c|}
\hline Especificação & Tipo de laje & Armadura & Ensaio \\
\hline L-S-15-6D9,5_lote X & $\mathrm{S}, \mathrm{h}=15 \mathrm{~cm}, \mathrm{~L}=6,5 \mathrm{~m}$ e $\sigma_{\mathrm{pi}}=1423,42 \mathrm{MPa}$ & $6 \phi 9,5 \mathrm{~mm}$ & $\begin{array}{c}1 \text { Cisalhamento } \\
2 \text { Flexão }\end{array}$ \\
\hline L-S-20-8D12,7_lote X & $\mathrm{S}, \mathrm{h}=20 \mathrm{~cm}, \mathrm{~L}=6,5 \mathrm{~m}$ e $\sigma_{\mathrm{pi}}=1425,05 \mathrm{MPa}$ & $8 \phi 12,7 \mathrm{~mm}$ & $\begin{array}{c}1 \text { Cisalhamento } \\
2 \text { Flexão }\end{array}$ \\
\hline L-C-20-6D9,5_lote X & C, UST, $h=20 \mathrm{~cm}, \mathrm{~L}=6,5 \mathrm{~m}$ e $\sigma_{\mathrm{pi}}=1423,42 \mathrm{MPa}$ & $6 \phi 9,5 \mathrm{~mm}$ & $\begin{array}{c}2 \text { Cisalhamento } \\
2 \text { Flexão }\end{array}$ \\
\hline L-C-25-8D12,7_loteX & C, UST, $h=25 \mathrm{~cm}, \mathrm{~L}=6,5 \mathrm{~m}$ e $\sigma_{\mathrm{pi}}=1425,05 \mathrm{MPa}$ & $8 \phi 12,7 \mathrm{~mm}$ & $\begin{array}{l}1 \text { Cisalhamento } \\
1 \text { Flexão }\end{array}$ \\
\hline \multirow{2}{*}{ L-S-20-5D12,7_lote Z } & $\mathrm{S}, \mathrm{h}=20 \mathrm{~cm}, \mathrm{~L}=3,1 \mathrm{~m}$ e $\sigma_{\mathrm{pi}}=1140 \mathrm{MPa}$ & \multirow{2}{*}{$5 \phi 12,7 \mathrm{~mm}$} & 5 Cisalhamento \\
\hline & $\mathrm{S}, \mathrm{h}=20 \mathrm{~cm}, \mathrm{~L}=6,10 \mathrm{~m}$ e $\sigma_{\mathrm{pi}}=1140 \mathrm{MPa}$ & & 1 Flexão \\
\hline \multirow{2}{*}{ L-C-25-5D12,7_lote Z } & C, UCT, $\mathrm{h}=25 \mathrm{~cm}, \mathrm{~L}=3,1 \mathrm{~m}$ e $\sigma_{\mathrm{pi}}=1140 \mathrm{MPa}$ & \multirow{2}{*}{$5 \phi 12,7 \mathrm{~mm}$} & 5 Cisalhamento \\
\hline & C, UCT, $h=25 \mathrm{~cm}, \mathrm{~L}=6,10 \mathrm{~m}$ e $\sigma_{\mathrm{pi}}=1140 \mathrm{MPa}$ & & 1 Flexão \\
\hline
\end{tabular}

Nota: S: sem capa; C: com capa; h: altura total da laje; L: comprimento da laje; $\sigma_{\mathrm{pi}}$ : tensão de protensão inicial; UST: sem tratamento da interface, UCT: com tratamento da interface.

Fonte: adaptado de CATOIA (2011). 
Assim, foram realizados 15 ensaios de cisalhamento, sendo 7 para as lajes sem capa e 8 ensaios para as lajes com capa. Quanto à flexão, foram realizados 9 ensaios, sendo 5 em lajes sem capa e 4 em peças com capa. Na Figura 5 estão apresentadas as tipologias das lajes ensaiadas.

As unidades com capa do lote Z receberam um tratamento na face superior, antes da concretagem da capa. Foram realizadas mecanicamente ranhuras longitudinais na interface e posteriormente foi realizada a limpeza com jato de água, de forma a eliminar as impurezas provenientes do processo de corte das unidades e da execução das ranhuras. Já as peças do lote $X$ não receberam qualquer tratamento, foram utilizadas da forma como se encontraram no pátio das fábricas, ou seja, com superfície lisa e empoeirada. As lajes foram produzidas com equipamento europeu e pelo método da extrusão, com o emprego de serra para conformação dos painéis.

\section{CISALHAMENTO EM LAJES SEM CAPEAMENTO ESTRUTURAL}

Os resultados experimentais $\left(\mathrm{V}_{\mathrm{u}, \exp }\right.$ - força cortante máxima obtida no ensaio) e teóricos ( $V_{\mathrm{Rk}}$ força cortante máxima teórica) das lajes sem capa ensaiadas ao cisalhamento e as configurações de fissuração podem ser observados na Figura 6 e 7, respectivamente.
Com a Figura 6 é possível observar que a maioria das lajes sem capa, tanto do lote $X$ como do lote $Z$, apresentaram resultados satisfatórios, sendo os valores experimentais superiores aos previstos teoricamente. Apenas uma laje não atendeu ao previsto (L7).

Por meio da análise dos mecanismos resistentes das unidades com a aplicação da força, foi possível notar que a laje de menor altura (L1) apresentou maior influência da flexão em relação aos demais elementos. Como pode ser observada na Figura 7, a laje L1 rompeu devido ao mecanismo de flexão, resultando na compressão da borda superior. Na laje L2, inicialmente apareceram fissuras de flexão, entretanto a ruptura ocorreu pela combinação dos mecanismos de flexão e cisalhamento, resultando no fendilhamento do concreto devido à falha de ancoragem. Ao longo do ensaio, o aumento da força aplicada gera o aumento da concentração de tensões de tração nas armaduras ativas até que a capacidade resistente da ancoragem é alcançada, a partir dai ocorre o escorregamento das barras e o consequente fendilhamento do concreto presente nessa região.

As lajes sem capa do lote $Z$ apresentaram interação de flexão, cisalhamento e falha de ancoragem, na região próxima ao apoio. Entretanto, constatou-se a presença de torção na laje L7, que rompeu pela interação de cisalhamento, flexão e torção, e não atingiu a máxima capacidade prevista.

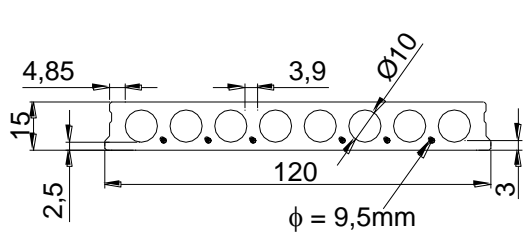

L-S-15-6D9,5_lote X

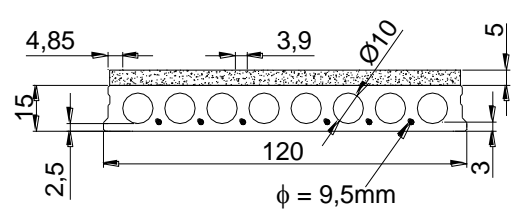

L-C-20-6D9,5_lote X

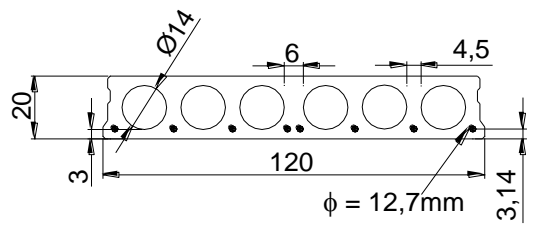

L-S-20-8D12,7_lote X

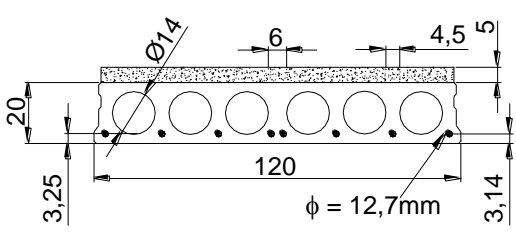

L-C-25-8D12,7_lote X

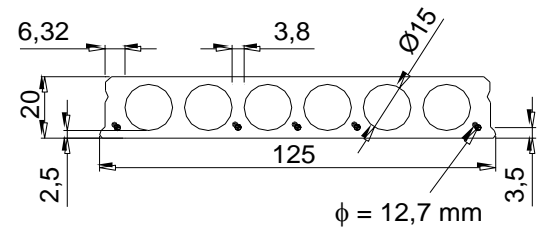

L-S-20-5D12,7_loteZ

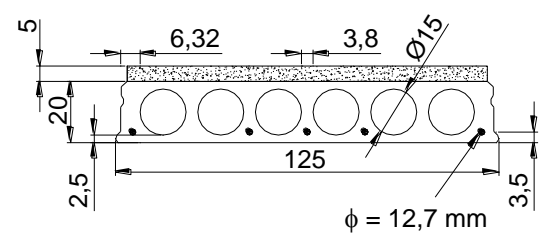

L-C-25-5D12,7_loteZ

FIGURA 5: Tipologia das lajes ensaiadas FONTE: CATOIA (2011). 

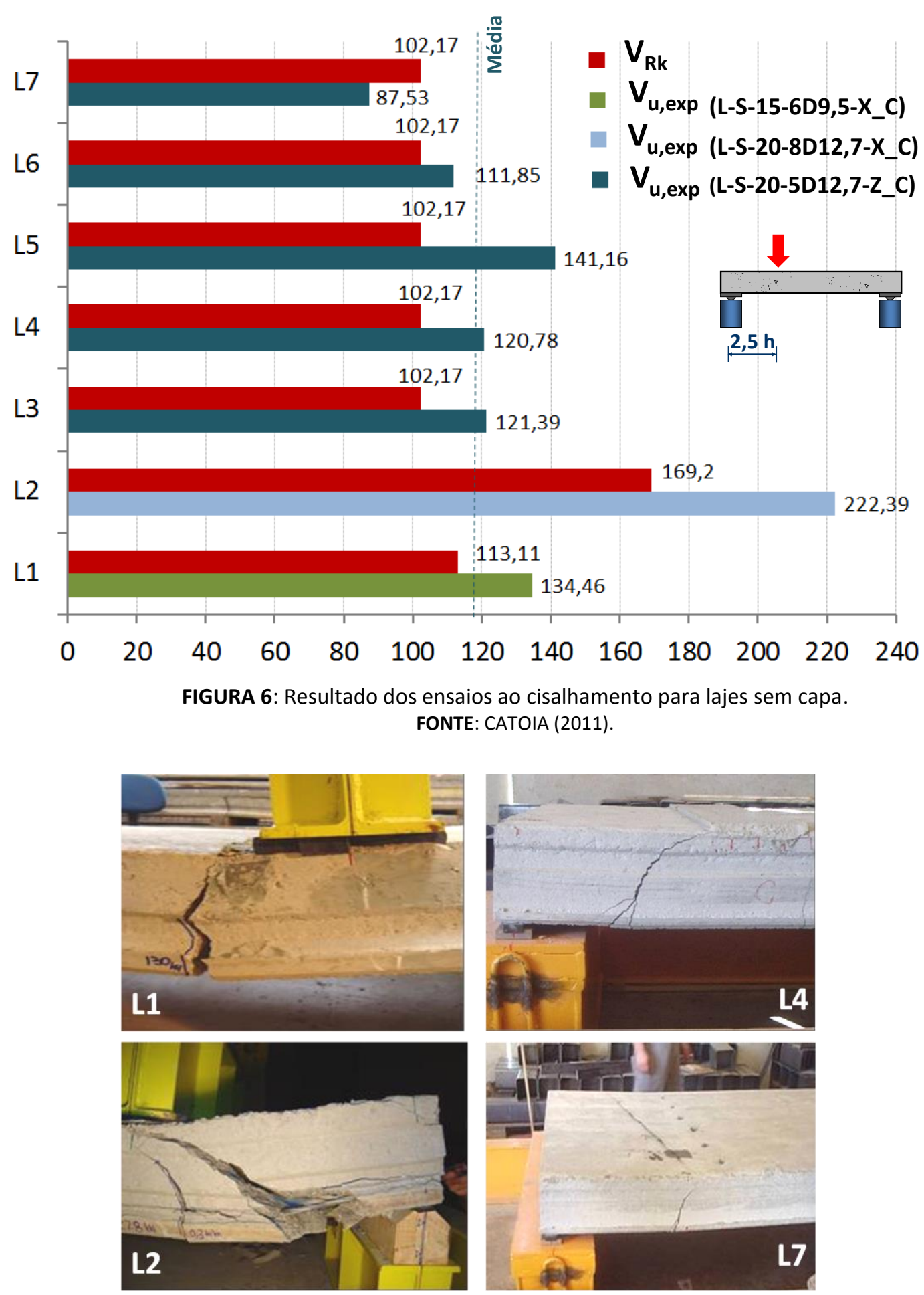

FIGURA 7: Configuração de fissuração das lajes sem capa ensaiadas ao cisalhamento.

FONTE: CATOIA (2011).

\section{CISALHAMENTO EM LAJES COM CAPEAMENTO ESTRUTURAL}

A partir da Figura 8, pode-se observar que todas as lajes com capa do lote $Z$ apresentaram resultados satisfatórios. Já as lajes do lote $X$ apresentaram valores experimentais inferiores aos previstos teoricamente. Somente a laje L3, a de maior altura $(25 \mathrm{~cm})$, apresentou a relação equivalente a 0,96 , sendo aceitável para esse caso, de acordo com o critério da nova revisão da EN 1168 (CEN 2005). 


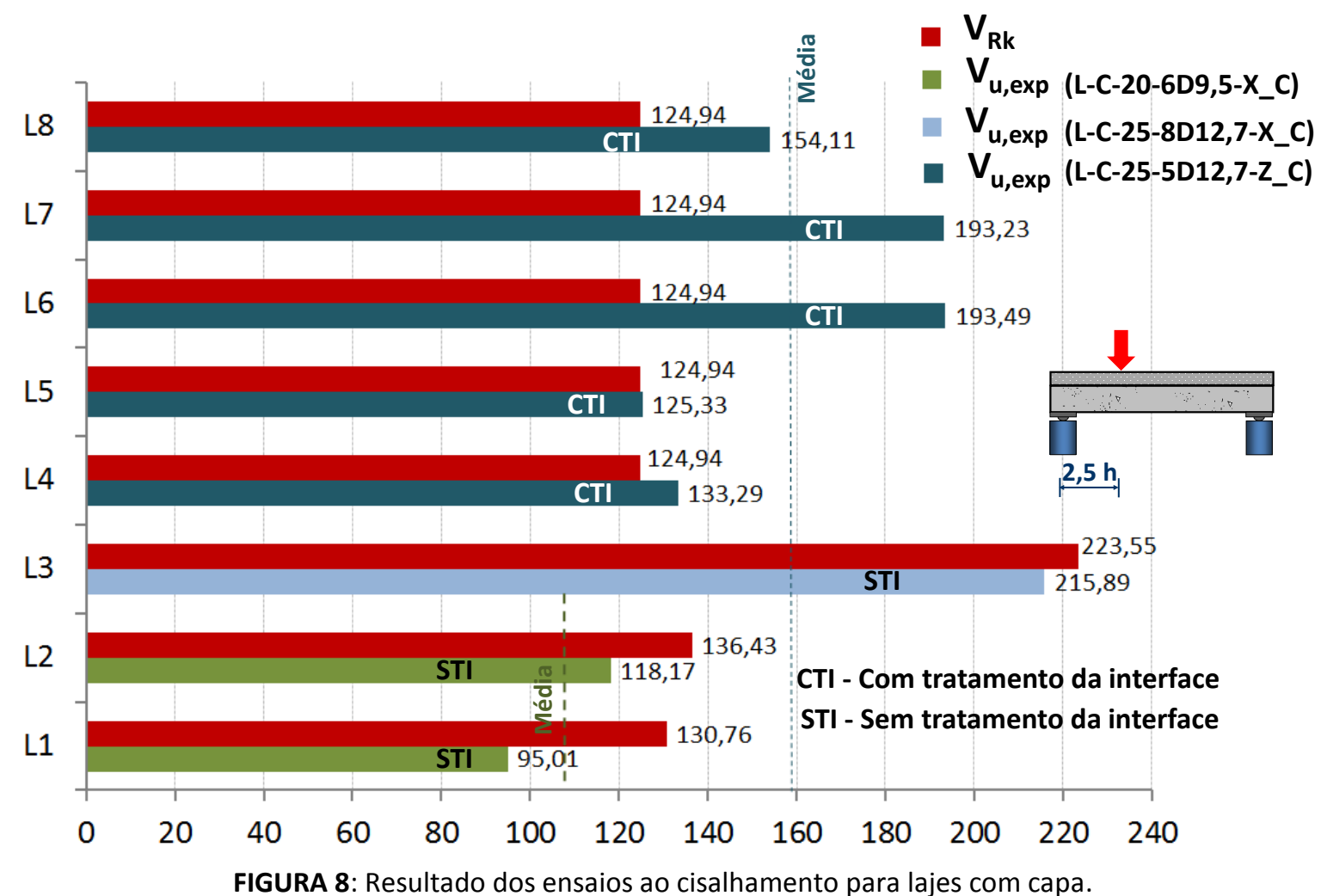

FONTE: CATOIA (2011).

Da mesma forma que observado anteriormente, constatou-se que as lajes de menor altura (L1 e L2) apresentaram maior influência do mecanismo de flexão, como pode ser observado na Figura 9. Além disso, nessas lajes observou-se a presença de fissura horizontal na interface, configurando o descolamento prematuro da capa.
Já as demais lajes, de maior altura, apresentaram fissuras mais bem definidas quanto ao cisalhamento, especialmente a laje L3 que apresentou ruptura típica de cisalhamento, com a fissura ligando o ponto de apoio ao ponto de aplicação de força. Além disso, houve o descolamento da capa e a fissuração acima do alvéolo.
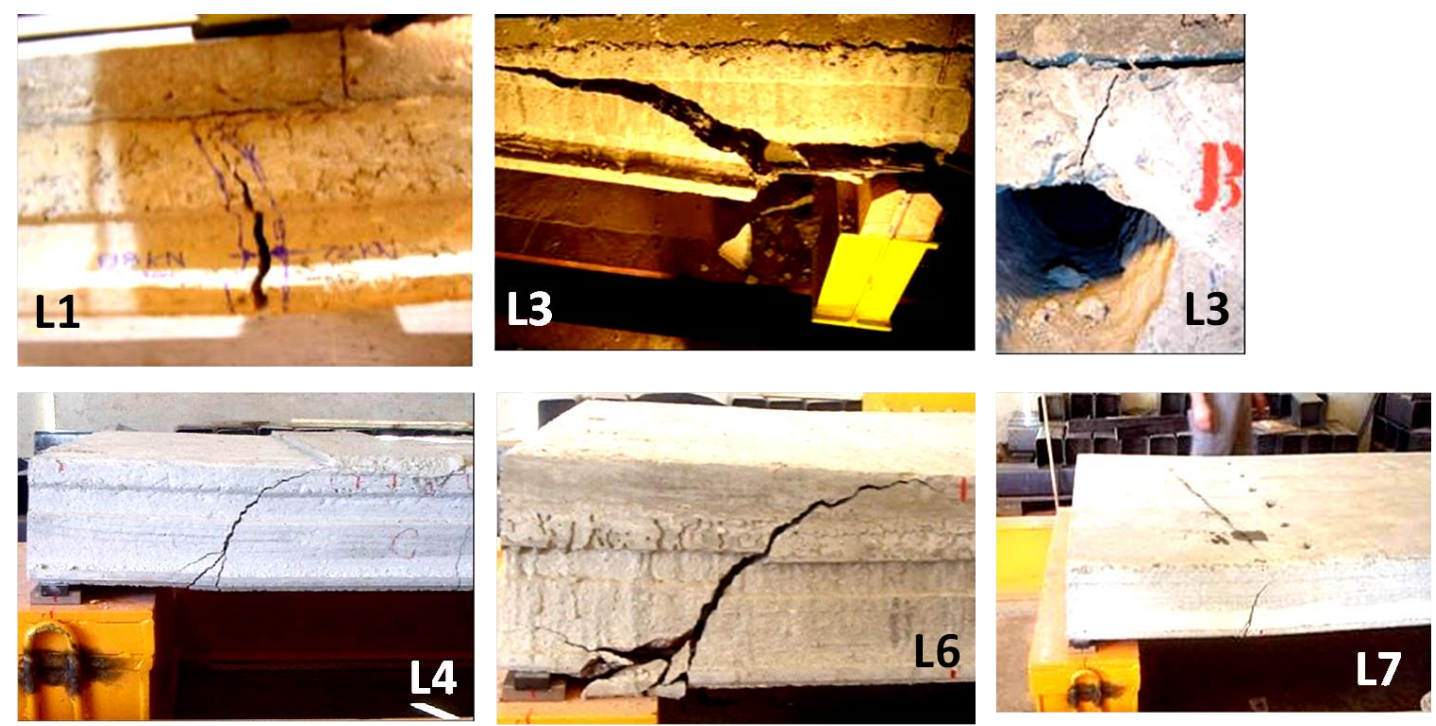

FIGURA 9: Configuração de fissuração das lajes com capa ensaiadas ao cisalhamento FONTE: CATOIA (2011). 
Nas lajes do lote $Z$ não houve 0 descolamento das capas, foi constatada boa aderência entre a laje e a capa, uma vez que a fissuração se estendeu através da região de interface. Esse comportamento pode ser observado por meio da configuração de fissuração das lajes $L 4$ e L6, ilustrada na Figura 9. Assim, com o ensaio constatou-se que nas lajes do lote $Z$, a seção trabalhou efetivamente como uma seção composta.

É importante ressaltar que justamente nas lajes provenientes da empresa $Z$ houve 0 tratamento da interface antes da execução da capa de concreto moldado no local, ou seja, a interface apresentou-se rugosa e limpa.

\section{FLEXÃO EM LAJES SEM CAPEAMENTO ESTRUTURAL}

Os resultados experimentais $\left(\mathrm{M}_{\mathrm{u}, \mathrm{exp}}-\right.$ momento fletor máximo obtido no ensaio) e teóricos $\left(\mathrm{M}_{\mathrm{Rk}}\right.$ - momento fletor máximo teórico) quanto à flexão e a configuração de fissuração de algumas lajes podem ser observados nas Figuras 10 e 11 , respectivamente.

De acordo com a Figura 10, as lajes sem capa alcançaram resistência à flexão superior à esperada teoricamente. Entretanto, observou-se no ensaio que as lajes com altura de $20 \mathrm{~cm}$ ( $L 3$ e L4) apresentaram um comportamento mais dúctil com relação às lajes menores.

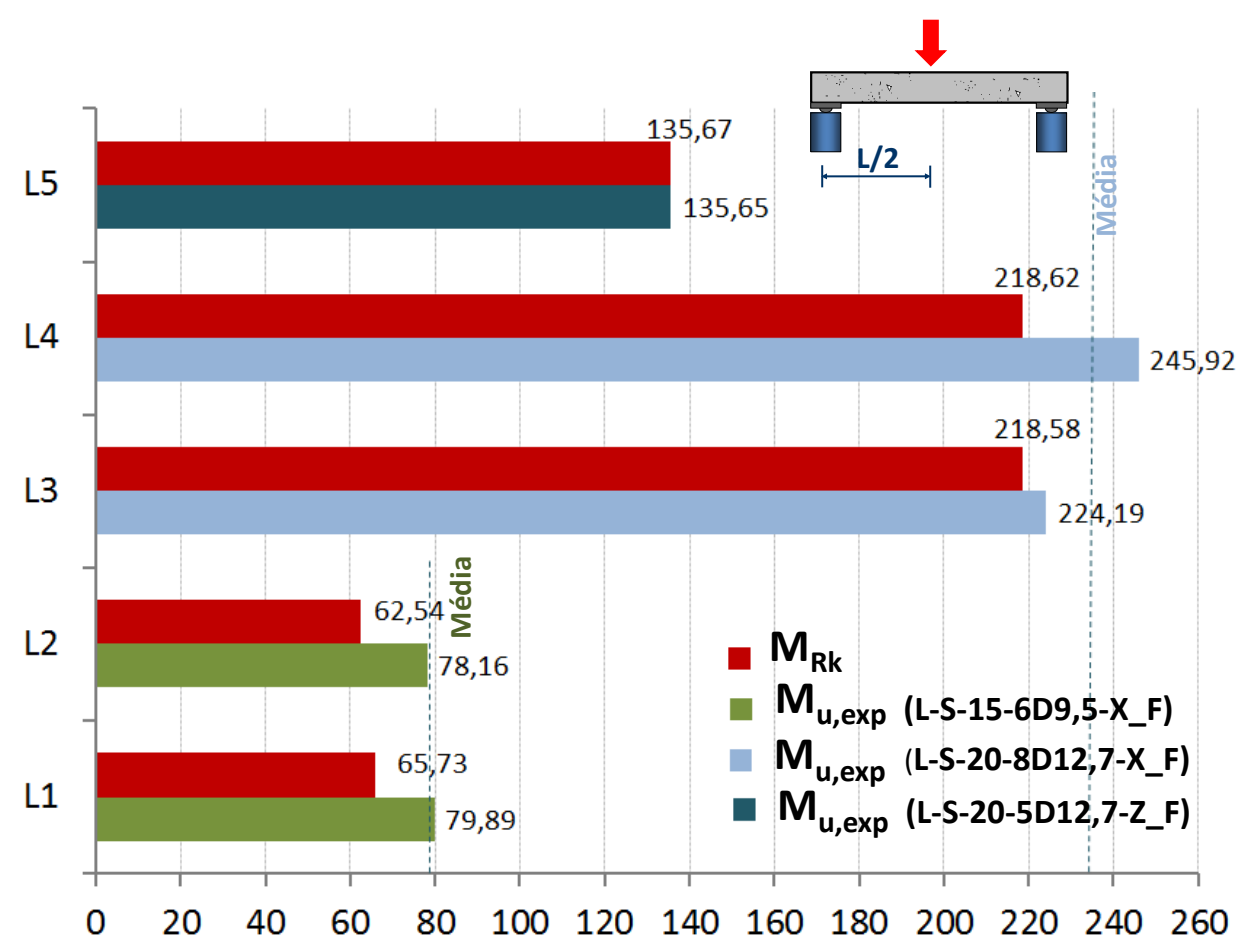

FIGURA 10: Resultados dos ensaios à flexão para as lajes sem capa. Fonte: CATOIA (2011).

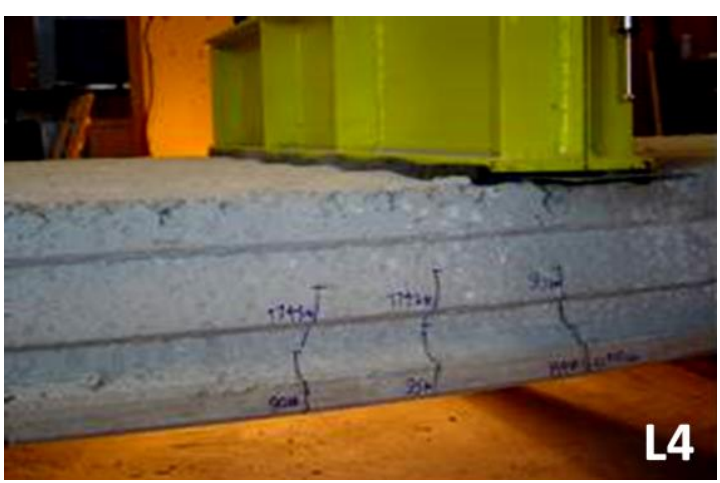

FIGURA 11: Configuração de fissuração das lajes sem capa ensaiadas à flexão FONTE: CATOIA (2011). 


\section{FLEXÃO EM LAJES COM CAPEAMENTO ESTRUTURAL}

De acordo com a Figura 12, as lajes com $20 \mathrm{~cm}$ de altura (L1 e L2) apresentaram comportamentos semelhantes e valores superiores aos obtidos teoricamente. Entretanto, foi observado o descolamento da capa durante o ensaio de flexão (Figura 13). A laje com altura de $25 \mathrm{~cm}$ (L3) apresentou resistência inferior ao esperado, sendo também observado o descolamento da capa, próximo à ruptura da peça. Da mesma forma que para as lajes sem capa, a laje com capa de maior altura apresentou um comportamento mais dúctil (considerando flexão) com relação às demais.

Semelhante à laje sem capa, a laje com capa e vão de $6,0 \mathrm{~m}$ (L4), do lote $Z$ apresentou resultado experimental satisfatório.

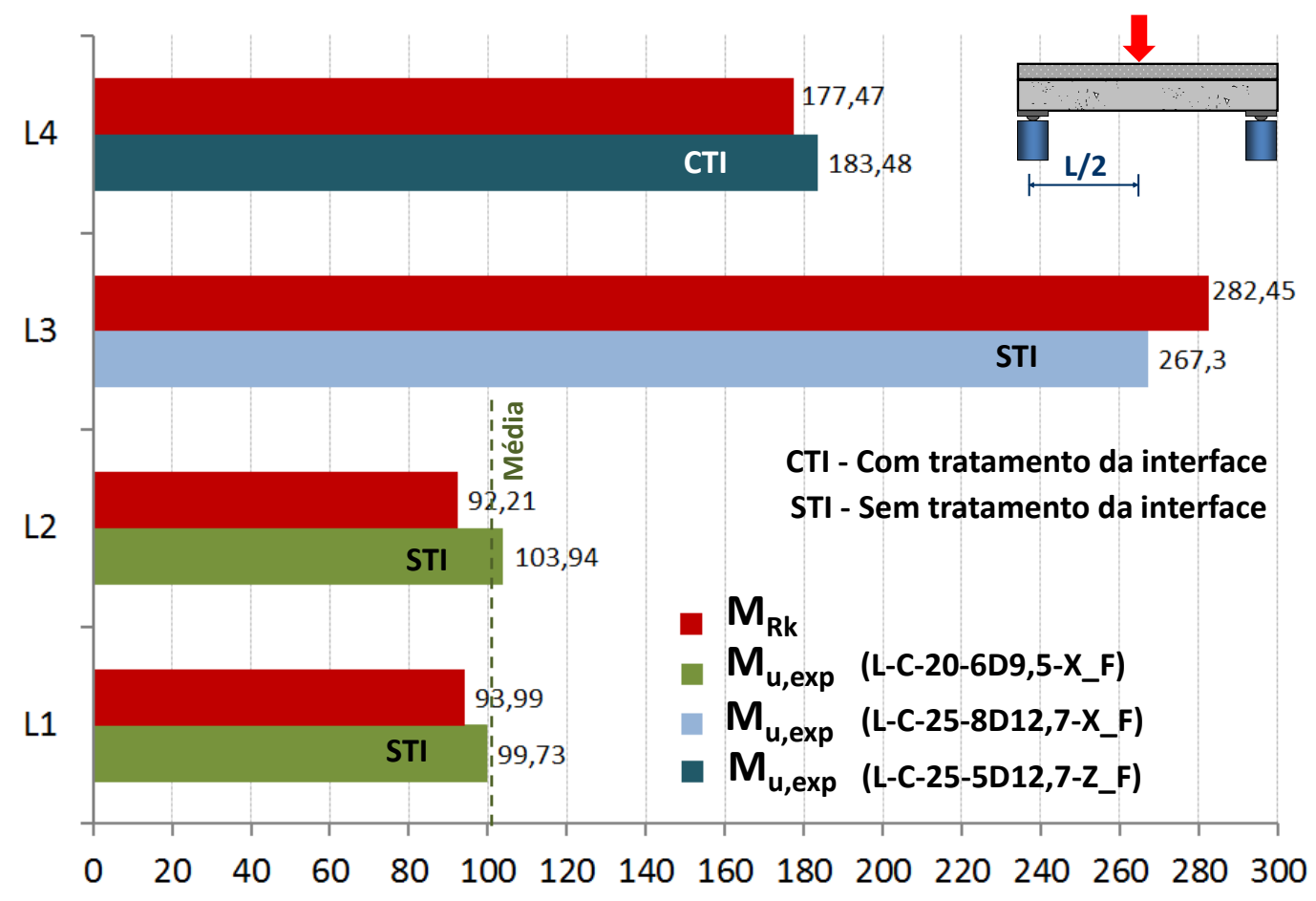

FIGURA 12: Resultados dos ensaios à flexão para lajes com capa FONTE: CATOIA (2011).
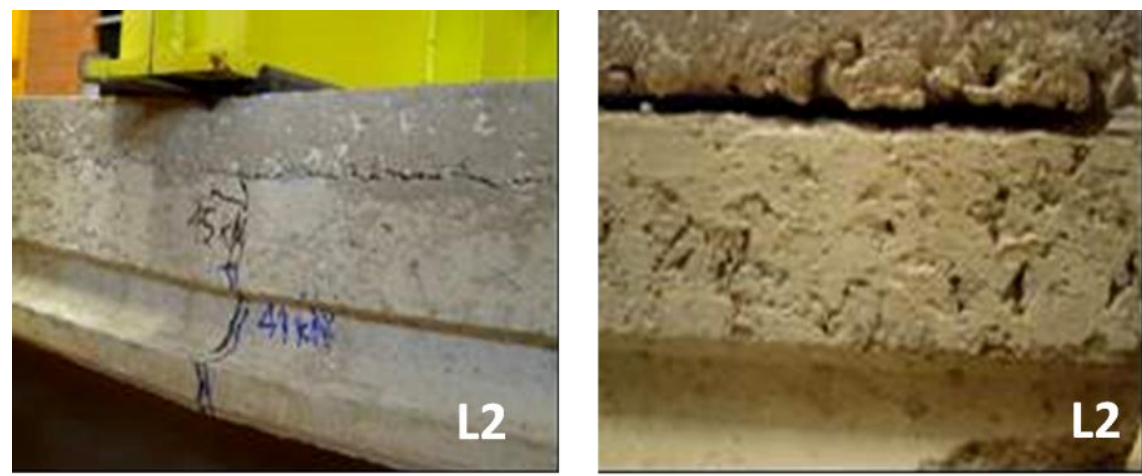

FIGURA 13: Configuração de fissuração das lajes com capa ensaiadas à flexão FONTE: CATOIA (2011). 


\section{ANÁLISES E DISCUSSÕES}

Para diferentes situações de projeto, espera-se que peças com capa apresentem resistências superiores às daquelas sem capa. Entretanto, a partir dos resultados observou-se que isso não se concretizou para todos os casos. De uma forma geral, é possível notar que as peças sem capa pertencentes ao lote $X$ apresentaram resultados ao cisalhamento superiores aos obtidos pelas peças semelhantes, com a presença de capa. Isso pode ser verificado comparando a laje sem capa $L 1$ com as lajes com capa L1 e L2 e comparando a laje sem capa L2 com a laje com capa L3 (Figura 14).

Assim, diferentemente do esperado, a presença da capa prejudicou o desempenho da unidade ao cisalhamento. Isso pode ser explicado pela falta de aderência entre a capa e a laje, uma vez que propositadamente não houve qualquer tratamento da face superior da laje, quanto à rugosidade ou limpeza antes da concretagem da capa, justamente nas peças pertencentes ao lote $X$. A falta de aderência entre a capa e a laje prejudica o desempenho da unidade. Isso ocorre porque quando a capa é considerada tem-se um aumento do peso próprio e, consequentemente, da distância da aplicação de força (pois o considerado é 2,5 h, sendo $\mathrm{h}$ a altura total do modelo). Essa solicitação adicional gera um aumento do momento fletor na seção considerada, que deve ser resistido pela seção composta. Entretanto, sem a aderência entre as partes, somente a laje será submetida a tais solicitações, tendo seu desempenho afetado.

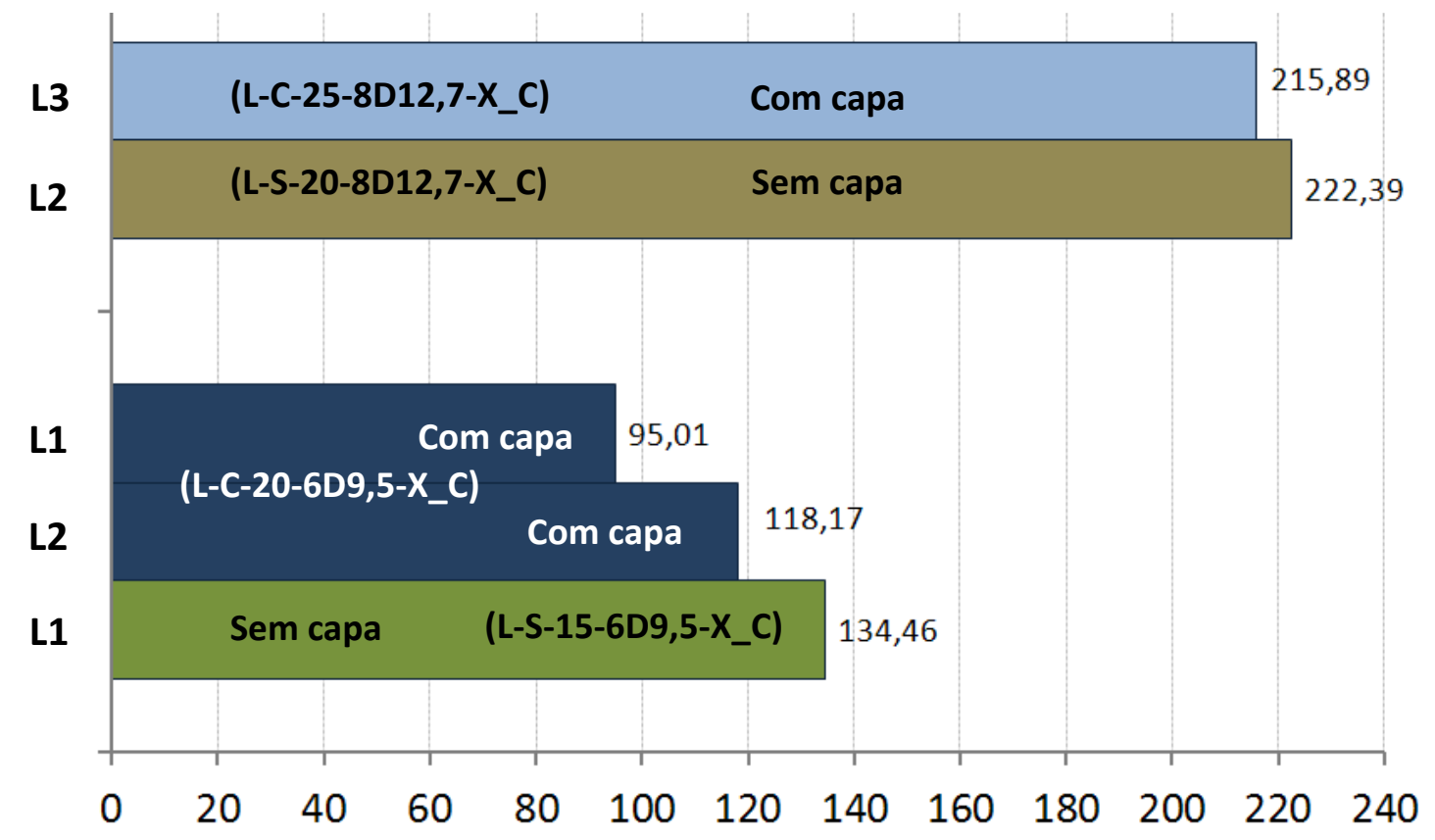

FIGURA 14: Valores experimentais ao cisalhamento para lajes semelhantes com e sem capeamento estrutural. FONTE: CATOIA (2011). 


\section{CONCLUSÕES}

Analisando a ruína das lajes, em alguns ensaios ao cisalhamento foi observada a presença do mecanismo de torção. A interação de mecanismos foi capaz de prejudicar o desempenho da unidade. Então, além de avaliar resultados é fundamental analisar os mecanismos resistentes e verificar se tais mecanismos são compatíveis com as equações empregadas.

A partir da análise das peças que apresentaram boas condições de aderência, foi observada a eficiência do emprego de capa na melhoria da capacidade resistente ao cisalhamento e à flexão, em unidades alveolares protendidas.

Assim, concluiu-se que, quando a seção se comporta efetivamente como composta, é possível obter aumentos significativos nas resistências ao cisalhamento e à flexão, como foi observado nas peças do lote $Z$, que apresentaram um aumento de $37 \%$ ao cisalhamento e $35 \%$ à flexão, com relação à peça semelhante, sem capa. Entretanto, como observado, quando a seção não trabalhar como composta, a capa pode prejudicar o desempenho quanto ao cisalhamento, resultando em resistências inferiores às obtidas pelas lajes do mesmo tipo, sem capa.

Comparando os resultados obtidos para as lajes compostas, conclui-se que os procedimentos empregados na concretagem da capa influenciam no desempenho da unidade alveolar. O tratamento da interface, mediante a criação de rugosidade superficial da face superior e a limpeza das peças antes da concretagem, é essencial para garantir a ação conjunta laje-capa.

Dessa forma, o processo de execução da capa corresponde a um aspecto de extrema importância na execução de estruturas de edifícios, principalmente quando essa capa é essencial para garantir o efeito diafragma, possibilitando o trabalho conjunto da estrutura.

\section{REFERÊNCIAS BIBLIOGRÁFICAS}

ASSOCIAÇÃO BRASILEIRA DE NORMAS TÉCNICAS (2011). NBR 14861: Lajes alveolares pré-moldadas de concreto protendido - Requisitos e procedimentos. Rio de Janeiro. 2011.

CATOIA, Bruna (2011). Lajes Alveolares Protendidas: Cisalhamento em Região Fissurada por Flexão. 325p. Tese (Doutorado) - Escola de Engenharia de São Carlos, Universidade de São Paulo, São Carlos, 2011.

COMITÉ EUROPÉEN DE NORMALISATION, CEN (2005). EN 1168:2005, Precast concrete products - Hollow core slabs. Brussels. 2005.

ELLIOTT, K.S. (2005). I Workshop Internacional: Design and construction of precast concrete structures. São Carlos, UFSCar - NETPRE. 2005.

FEDERATION INTERNATIONALE DE LA PRECONTRAINTE. (FIP) (1982). FIP Guide to Good Practice - Shear at the Interface of Precast and In-situ Concrete. Wrexham Springs. 1982.

FEDÉRATION INTERNATIONALE DE LA PRÉCONTRAINTEFIP (1992). Guide to good practice: quality assurance of hollow core slab. London, England. 1992.

IBRAHIM, Izni Syahrizal bin (2008). Interface Shear Strength of Hollow Core Slabs with Concrete Toppings. Thesis - University of Nottingham, United Kingdom, 2008. 